\title{
Nem redefinições, nem dissoluções, nem aproximações fazem os fins justificarem os meios: uma réplica
}

\author{
Gustavo Daou Lucas ${ }^{1}$ \\ Franklin Serrano ${ }^{2}$
}

\section{Introdução}

Nesta nota respondemos aos comentários de Camarinha Lopes (2019) acerca de um artigo nosso publicado neste periódico (Daou Lucas \& Serrano 2018). Naquele trabalho, alegamos que as tentativas recentes de resolver o 'problema da transformação' têm contribuição positiva questionável. Isto porque: (i) o problema que do ponto de vista econômico e matemático fora exaustivamente discutido e considerado de solução geral relevante impossível (Daou Lucas 2017) e (ii) as supostas soluções recentes não passariam de redefinições que alteram o conteúdo do problema original. De forma simplificada, muda-se o problema e sua solução é "realizada" por suposição, dado que os termos originais do debate já não estão mais presentes.

Como se sabe, soluções satisfatórias para o problema de determinar a distribuição entre salários e lucros e os preços relativos usando como parâmetros as condições técnicas de produção e a cesta de mercadorias (que serve de referência para o salário) existem há mais de cem anos (Daou Lucas 2017). Dado que o método da transformação usado por Marx é apenas uma forma (problemática) de resolver este problema, o suposto "problema da transformação" (expressão inexistente em Marx) é um falso problema e a sua solução é desnecessária e impossível (nos termos tradicionais do debate).

1 Professor - Instituto de Economia - Universidade Federal do Rio de Janeiro (UFRJ).

Endereço: Av. Pasteur, 250 - Palácio Universitário, sala 106 - Urca - Rio de Janeiro/RJ - Brasil CEP: 22290-240 - E-mail: gustavodlucas@gmail.com - ORCiD: https://orcid.org/0000-0002-6130-1275.

2 Professor - Instituto de Economia - Universidade Federal do Rio de Janeiro - Endereço: Av. Pasteur, 250 - sala 109, Urca - Rio de Janeiro/RJ - Brasil - CEP: 22290-240 - E-mail: franklin@ie.ufrj.br ORCiD: 0000-0002-9981-9029.

Recebido: 01/11/2019. Aceite: 03/12/2019.

Editor Responsável: Rogério Arthmar

(c) (i) (\$) Esta obra está licenciada com uma Licença Creative Commons Atribuição-Não Comercial 4.0 Internacional. 
Em seu comentário, Camarinha Lopes (2019) apresenta uma série de críticas ao nosso trabalho, mas, de uma forma geral, considera que os argumentos que apresentamos são analiticamente corretos. A nosso ver, existe uma série de contradições nesse comentário. Adicionalmente, nosso crítico parece admitir que as "novas soluções" que criticamos não resolvem o problema (ele chega a chamá-las de "tentativas desesperadas"), mas paradoxalmente diz que a versão do Sistema Temporal Único (STU) "é a mais desenvolvida". Finalmente, contradizendo sua primeira crítica (i.e., a ideia de que as proposições analíticas corretas não são o ponto central nesta área), afirma que nossa análise estaria defasada em relação à fronteira de pesquisa sobre o tema, pois não consideramos em nosso texto contribuições analíticas de outras supostas novas soluções mais recentes, como as de Schefold (2016) e Wright (2019). ${ }^{l}$ Nas sessões a seguir comentamos esses pontos em maior detalhe. ${ }^{2}$

\section{Implicações Políticas antes, Proposições Analíticas depois}

O objetivo de Marx com sua teoria do valor era entender as leis científicas de funcionamento e movimento da economia capitalista, de forma que sem uma teoria para o funcionamento do sistema que seja correta do ponto vista analítico, qualquer conclusão política relevante (ou eventuais juízos morais ou éticos sobre contradições e injustiças desse sistema) seria simplesmente sem fundamento e, por definição, mero a priori ideológico. Esse papel de entender as 'leis do capitalismo usando o mesmo método das ciências naturais ${ }^{3}$ parece escapar a nosso crítico. Ou seja, ao contrário do que parece pensar Camarinha Lopes (2019), a teoria marxiana do valor não é uma teoria de justiça distributiva ou ética, mas uma teoria econômica. E para poder explicar o caráter objetivo da oposição de interesses de

1 É importante observar que este é um trabalho posterior ao nosso.

2 Sobre a possibilidade do STU ser a versão mais avançada do tema, por falta de espaço e para não repetirmos argumentos prévios, ver Daou Lucas \& Serrano (2018). De forma sintética, pode-se dizer que nessa formulação não há uma definição clara de equilíbrio e desequilíbrio, de forma que as proposições - a despeito da notação matemática aparentemente sofisticada - desses autores são tautológicas. Consideramos que esta abordagem é, na verdade, a mais problemática de todas.

3 "(...) it is always necessary to distinguish between the material transformation of the economic conditions of production, which can be determined with the precision of natural science, and the legal, political, religious, artistic or philosophic- in short, ideological forms in which men become conscious of this conflict and fight it out" (Marx 1859). 
classes no capitalismo, Marx considerava que uma teoria do valor correta era essencial como instrumento científico.

Segundo o nosso crítico, a contribuição feita por nós seria correta analiticamente, mas incorreta "politicamente". Tendo claro o ponto do parágrafo anterior, podemos ver que essa conclusão não possui maior fundamento. Além de abertamente propor uma espécie de "engenharia reversa" para chegar a conclusões políticas particulares, nosso crítico parece atribuir esta mesma prática a Marx. Como observamos, não há evidência textual que permita defender essa interpretação.

Camarinha Lopes (2019) afirma ainda que até os anos 1970 não se sabia publicamente qual era a posição ideológica e política de Sraffa, como se sabe hoje, e que voltar ao consenso analítico da época seria "complicar ainda mais a comunicação entre os seguidores de Marx e Sraffa”. Por que deveríamos julgar diferente a contribuição de um autor só porque agora sabemos sua posição política? A filosofia da ciência carece de um consenso sobre o que seria o critério de demarcação científica, mas nenhum filósofo da ciência relevante defenderia que a análise científica seja diretamente dependente da ideologia dos que a praticam. Nada mudaria no significado econômico dos resultados analíticos de Sraffa se, hipoteticamente, fosse descoberto que este era um libertarian!

Ou seja, além de não ser uma teoria ética ou moral, é ainda possível afirmar que as conclusões políticas (ou éticas e morais para alguns de seus intérpretes) que interessavam a Marx dependiam de sua teoria do valor estar correta. Do contrário, seria impossível entender porque Marx considerava alguns economistas como 'vulgares' (i.e., sem contribuição analítica, meros apologistas do capitalismo) e outros, 'clássicos', ou "científicos", como D. Ricardo ou F. Quesnay. Os últimos, apesar de restritos pelo que Marx chamava de "horizonte burguês de análise" (i.e., economistas que naturalizavam as instituições do capitalismo), ${ }^{4}$ ainda assim eram considerados como tendo contribuições científicas relevantes, conforme reportado em diversas passagens de seu livro póstumo de história da teoria econômica, Teorias da Mais Valia.

4 Isto é, a forma extremamente concentrada como a propriedade dos meios de produção é distribuída, como funciona o sistema de leis e direitos de propriedade etc. 
Assim, fica claro também que não podemos julgar cientificamente a teoria marxiana do valor (ou de qualquer outro autor) simplesmente porque ela possui uma implicação política ou moral que agrada ao a priori ideológico de alguns pesquisadores (mas também desagrada a tantos outros). Sem uso do método analítico, dificilmente Marx teria sido influenciado por Ricardo, pois não partilhava da ideia de que teoria ricardiana era inseparável da visão liberal de mundo do mesmo, que Marx evidentemente rejeitava. $^{5}$

\section{A Questão da Exploração da Força de Trabalho}

A preocupação de nosso crítico de que a rejeição das novas soluções, ou qualquer crítica ao método da transformação, teriam tais consequências políticas negativas parece se basear na ideia, ainda muito difundida em alguns meios marxistas, de que a demonstração da existência de exploração do trabalho por parte dos proprietários dos meios de produção dependeria da existência de uma solução para o problema da transformação.

Consideramos que a análise dos conflitos de classe em termos do conceito de exploração depende de uma análise mais geral das relações de poder e da estrutura de propriedade que caracteriza o capitalismo. Mas isso não depende do fato de que os preços relativos das mercadorias desviam ou não das quantidades de trabalho incorporadas nas mesmas, ou da taxa de lucro ser calculada simultaneamente à determinação dos preços relativos ou não. Por exemplo, o fato da medição do excedente ser realizada em trabalho como Marx ou em mercadorias como Sraffa em nada muda a realidade das relações sociais assimétricas de poder que permitem a reprodução e distribuição deste mesmo excedente (ver Garegnani 2018).

5 Teria sido também impossível L. Bortkiewicz apresentar o que chamava de "correção" do sistema marxiano, assim como o fato de que autores que não se conheciam pessoalmente e viviam em países tão distantes como Japão e Alemanha chegarem a soluções tão parecidas no fim do século XIX e início do século XX sobre a necessidade de determinar preços e lucro simultaneamente e sobre a impossibilidade das duas invariâncias marxianas no caso geral (Daou Lucas 2017). 


\section{A Dissolução e a Aproximação}

Wright (2019) parte da conceito de "coeficiente de trabalho verticalmente hiper-integrado" usado por Pasinetti (1988), que consiste na quantidade de trabalho direta e indiretamente necessário para a produção de uma mercadoria (como o conceito de valor-trabalho tradicional), acrescido das quantidades de trabalho direto e indireto necessários à produção dos bens de capital essenciais para expandir a produção da mesma mercadoria a uma taxa de crescimento de pleno-emprego (uniforme para todos os bens) adicionada da taxa de crescimento do consumo per capita dessa mercadoria (que pode ser diferente para os diferentes bens).

$\mathrm{O}$ autor modifica ulteriormente esse conceito, chamando de "valor-trabalho" dos bens de consumo que entram na cesta salarial dos trabalhadores, a soma do trabalho direto e indireto necessário para reproduzir este bem, acrescido das quantidades diretas e indiretas de trabalho adicionais necessárias para o setor crescer a taxa que de fato estiver crescendo (de forma similar a Pasinetti) e, adicionalmente a Pasinetti, as quantidade de trabalho direto e indireto necessárias para a produção dos bens consumidos pelos capitalistas que tiveram lucro neste setor. Esta peculiar soma de requisitos de trabalho - que o autor considera uma generalização da teoria do valor trabalho - é o que o autor chama de "coeficiente de trabalho verticalmente super-integrado".

Tanto o conceito de Pasinetti quanto o peculiar conceito de Wright, além de não serem o valor-trabalho marxiano tradicional, também não servem para determinar a taxa de lucro e os preços relativos. O próprio Wright (2019, p.2) parece ter dificuldade para explicar para que serviria seu conceito, afirmando que "I solve, or more precisely dissolve, Marx's transformation problem, and Pasinetti's generalisation of it", pois suas equações pressupõem implicitamente que a taxa de lucro e os preços relativos já são conhecidos. Portanto, a dissolução de Wright (2019) tem em comum com as "novas soluções" criticadas em nosso artigo apenas o fato de fazer redefinição arbitrária do conceito de valor trabalho. De diferente, esta contribuição é admitidamente uma "dissolução" (i.e., elimina o problema original). 
Em relação à contribuição recente de Schefold (2014), é importante observar que se trata de um trabalho que usa exatamente os termos do debate original sobre a transformação e que tece críticas similares às nossas em relação à Nova Interpretação ("little more than a tautology", p.70). Portanto, não há qualquer relação analítica entre as contribuições que criticamos no nosso trabalho e o trabalho de Schefold. O autor não se propõe realmente a prover uma nova solução, mas sim uma demonstração de que válidos certos pressupostos estatisticamente, ${ }^{6}$ os desvios entre valores e preços de produção compensariam no agregado e a taxa de lucro calculada em valores seria igual a calculada pelo procedimento simultâneo usual. Sendo esses pressupostos válidos empiricamente, ${ }^{7}$ isso poderia explicar a pouca curvatura das relações salários lucro estimadas a partir de matrizes insumo produto empíricas na visão deste autor.

Ou seja, é uma contribuição que tem o mérito de aceitar os termos do debate tradicional e cujas conclusões dependem da validade empírica dos pressupostos - o que é completamente diferente das contribuições analisadas por nós no survey. É importante reiterar que não é uma tentativa de solução strictu sensu como as que discutimos, mas uma demonstração de quais condições deveriam valer empiricamente para que a transformação fosse um procedimento aproximadamente correto.

\section{Conclusão}

Soluções corretas para o problema que preocupava Marx confirmam o resultado central da relação inversa entre a taxa geral de lucro e o salário real, além de já existirem há mais de um século. A maioria dos autores que contribuiu para essa teoria considera que, ao confirmarem a oposição entre salários e lucros, as proposições não afetam a análise da relação entre capital e trabalho em termos de uma relação de exploração e as eventuais implicações políticas (e/ou éticas e morais) que decorreriam (i.e., que não são pressupostos) desta análise.

6 Ver Mohun \& Veneziani (2018, p.28) para uma análise dos pressupostos usados por Schefold.

7 Como o autor reconhece: "whether it is fulfilled in reality is, as with all the other assumptions, an empirical question" (p. 175). 
Quanto as duas contribuições recentes mencionadas no comentário, temos que a de Wright (2019) trata de mais um conjunto de redefinições conceituais que sequer se propõe realmente a solucionar o problema da transformação conforme originalmente concebido. Já a contribuição de Schefold (2016) é, como o próprio reconhece, um caso particular interessante da solução simultânea tradicionalmente usada por ele e outros autores.

Por último, gostaríamos de reiterar nossa rejeição à defesa de resultados questionáveis por motivos políticos. Acreditamos que somente uma confusão conceitual pode levar alguém a defender as "novas soluções" e simultaneamente reconhecer que estas não resolvem o problema que se propõem a enfrentar, alegando que seria uma contribuição para demonstrar a validade de uma suposta "teoria do valor dos trabalhadores".

\section{Referências}

Camarinha Lopes, T. (2019). Um comentário sobre o antigo consenso no debate sobre a transformação dos valores em preços de produção. Estudos Econômicos.

Daou Lucas, G. 2017. A re-rehabilitação da teoria clássica e o "problema da transformação". Economia e Sociedade, Campinas, v. 26, no. 3(61), p.633-662

Daou Lucas, G., Serrano, F. (2018). Valores-Trabalho através de uma Sucessão de Redefinições: Uma Análise das "Novas Soluções” para o "Problema da Transformação". Estud. Econ. [online], vol.48, no.3, pp.525-554.

Garegnani (2018) On the Labour Theory of Value in Marx and in the Marxist Tradition, Review of Political Economy, DOI: 10.1080/09538259.2018.1509546

Marx, K. (1859) Contribution to the Critique of Political Economy. Trans. S. W. Ryazanskaya; ed. Maurice Dobb. London: Lawrence \& Wishart, 1981.

Mohun, S., Veneziani, R. (2018). The logic of the transformation problem. Journal of Economic Surveys (2017) Vol. 00, no. 0, pp. 1-34

Schefold, B. (2016) Profits equal surplus value on average and the significance of this result for the Marxian theory of accumulation. Cambridge Journal of Economics 2016, 40: 165-199.

Wright, I. (2019) Marx's transformation problem and Pasinetti's vertically integrated subsystems, Cambridge Journal of Economics, Volume 43, Issue 1, 17 January 2019, Pages 169-186, 